\title{
Baños privados y termas públicas en el Lugo romano
}

\author{
C. Carreño *
}

Eran muy escasos, hasta hace poco tiempo, los estudios sobre urbanismo romano en el Noroeste de la penisula ibérica, escasez que se acentúa si de ciudades se trata. Las causas de esta penunria cabe buscarlas en la ausencia de excavaciones arqueológicas sistemáticas, poco abundantes en el medio rural y casi inexistentes en los ámbitos de los grandes núcleos de población.

De las capitales administrativas romanas, asi como de otros importantes centros urbanos, no se conocía otra cosa que los vestigios perdurantes en superficie, de lo que las murallas de Lugo contituyen el ejemplo más relevante, los hallazgos ocasionales, siempre fragmentarios y descoordinados, y, cuando más, los limitadísimos descubrimientos producidos por contadas intervenciones arqueológicas de urgencia.

En los últimos años, sin embargo, las cosas parecen haber ido a mejor. En Braga, por ejemplo, existe una unidad arqueológica encargada de efectuar excavaciones en la ciudad, unidad que, pese a las dificultades, va imponiendo sus líneas de actuación. La excavación en curso del gran complejo arqueológico de las termas en la colina de Maximinos constituye el ejemplo más destacado de su actuación.

En Astorga, la antigua Asturica Augusta, poco se habia hecho desde los tiempos de Luengo, si se exceptúan las cortas excavaciones de Mañanes en algunos sectores puntuales de la ciudad. Últimamente, tanto la Junta de Castilla-León, como el ayuntamiento mismo, han procurado remediar la penuria arqueológica arbitrando los medios humanos y materiales necesarios para el control e investigación arqueológicos del subsuelo urbano.

\footnotetext{
* Museo de Lugo.
} 
En Aquae Flaviae, Chaves, municipio romano, como es de todos conocido, se han producido en los dos últimos lustros importantes descubrimientos arqueológicos que afectan al urbanismo de la ciudad, el más destacado de los cuales es el del embalse y acueducto romanos que suministraban agua a la urbe. Los protagonistas de tales descubrimientos son Rodriguez Colmenero y su equipo, que, en breve, pretenden dar a conocer, en una amplia monografía, la labor arqueológica llevada a cabo desde 1985.

$Y$ antes de referirme a Lugo, ciudad sobre la que va a versar mi comunicación, no puedo dejar de hacer mención de otros dos núcleos romanos, de menor importancia jurídico-administrativa que los anteriores, pero no por ello de menos interés. Se trata de Gijón, tal vez la Gigia de Ptolomeo, en donde Carmen Fernández Ochoa está efectuando importantes descubrimientos, y Brigantium, La Coruña, campo de actuación sistemática en excavaciones de urgencia, primero de Juan Maveiro y ultimamente de Xan Vázquez.

Pero Lugo fue, sin duda, la ciudad, entre todas las del Noroeste, en donde la actividad arqueológica ha sido más intensa durante los últimos años. Todo empezó con la polémica de los aparcamientos subterráneos en 1986. Ello obligó a excavar en área, y en un tiempo record, dos grandes plazas situadas intramurallas. Después vino la excavación sistemática de todos los ámbitos edificables del casco histórico y sus aledaños y, finalmente, la constitución de unos Servicios Municipales de Arqueología, de los que soy responsable.

No pretendo ahora hacer una exposición detallada de todo lo que se lleva trabajado en la ciudad desde la fecha indicada sino centrarme solamente en un aspecto del urbanismo romano de la misma, el relacionado con las termas o baños tanto públicos como privados. Los primeros eran conocidos desde antiguo, los segundos constituyen la novedad. Podrá objetarse que no es éste, tal vez, el tema central de esta mesa redonda sino el culto a las aguas. Sin embargo, no se olvide que, por una parte, existe otra comunicación en este coloquio que trata de analizar la vertiente religiosa del ámbito urbano lucense en época romana y, por otra, la introducción de los baños públicos y privados por Roma entre los Galaicos debió de significar una novedad tal que puede considerarse su aceptación por parte de la población indigena como un auténtico gesto cultual. 


\section{TERMAS PRIVADAS}

\section{Plaza de Santo Domingo (lám. l,1)}

Estos baños privados aparecieron en el esquinal NW de un gran edificio incompletamente excavado, al que delimitaban, por el oeste, una estrecha calle porticada con pilastras de esquisto pizarroso y, por el norte, un amplio ámbito abierto, con varias etapas de formación, que en sus orígenes fue una vía de dimensiones normales perpendicular a la anterior. En todo caso, en el conjunto arqueológico son discernibles claramente dos niveles constructivos, detectables en las estructuras superpuestas que se han descubierto.

Precisamente, las instalaciones termales corresponden a la última de las etapas, como se deduce claramente de la disposición estratigráfica general.

El conjunto se compone de dos hipocaustos, de 2,50 por $1,60 \mathrm{~m}$ y 2 por $0,70 \mathrm{~m}$, respectivamente, comunicado el mayor con el praefurnium por medio de una boca rectangular practicada en el muro de separación, y con el menor por medio de una derivación oblicua practicada cave el vano



Lám. I, 1. Plaza de Santo Domingo. 
de comunicación con el praefurnium, que consiste en una pequeña estancia de 1,50 por $0,75 \mathrm{~m}$, en cuyo umbral se advertian tres hendiduras alineadas, cuyo cometido fue, sin duda, servir de encaje a la escotilla de cierre durante la combustión, escotilla cuya portezuela se deslizaba de arriba a abajo y viceversa por una ranura todavía visible en el muro de cierre septentrional cuando se llevó a cabo la excavación. Contiguos, por el sur, aparecen los muros de otra estancia de $3 \mathrm{~m}$ por 2,20. Más al este, otras salas en las que, como en la precedente, se descubrió la orla de mosaico que decoraba el suelo de sus habitaciones. Por otra parte, un canal de $0,30 \mathrm{~m}$ de anchura por una altura variable, hecho a base de paredes de pizarras horizontales asentadas en armasa, hecho de losas de la misma técnica y cubrición de lajas, asimismo de esquisto pizarroso, sin amalgama alguna, bordeaba en perfecto ángulo recto, con el vértice redondeado, los lados septentrional y occidental de la construción. Ahora bien, a la altura del borde exterior del muro de cierre del praefurnium y antes de doblar en ángulo hacia el sur, se sobreimponía a las paredes del canal, aquí notablemente elevadas, dado el desnivel del terreno, y en sentido transversal, otro muro de cierre, cuya continuación era la pared occidental del praefurmium.

Sin embargo, tras este corte transversal del conducto, continuaba éste enmarcado por unos muretes de mucho menor tamaño, aunque cubierto por losas de idéntica factura a las del primer tramo.

Indudablemente, dada la conjunción de hipocaustos y canalización de agua limpia, que otra cosa no puede ser el conducto al que nos venimos refiriendo, era lógico pensar en unas termas de pequeñas dimensiones, posiblemente de pertenencia privada. Cosa más difícil resultaba explicar su interrelación y funcionamiento, a la vista, sobre todo, de la ausencia de determinados vestigios que podrían resultar claves para el intento. No obstante, y tras larga reflexión, nos hemos aventurado a intentar la siguiente hipótesis, que creemos, por otra parte, sólidamente fundada.

En primer lugar, en el punto del canal en que este era cortado por el muro transversal debió de existir un resorte, a modo de guillotina, que, obturando cuando fuese preciso el pequeño specus del conducto, permitiría que el agua embalsada fuese subiendo de nivel hasta hacer rebasar, por un vertedero practicado en la paredilla sur del canal, el agua que serviria para llenar la más próxima de las piscinas, que sería la del caldarium, al que correspondería el hipocausto mayor. De aquí pasaría por una canalización a través de la salita del tepydarium hasta la tercera de las estancias, en donde estaría situado el frigidarium. Ignoramos la función de las demás estancias, bastantes de ellas recubiertas de magnificos mosaicos, de los que se conservaba solamente la orla exterior, pero su- 
ponemos que alguna de ellas habria servido de apodhyterium, si es que el tepydarium no funcionaba como estancia plurivalente. De todas formas, el vaciado de las piscinas se haría por orificios que no se conservan, hacia el tramo occidental del canal, que a partir de este momento se convertiria posiblemente en conducto de aguas sucias, lo que, dada la proximidad de una gran cloaca transversal, en la que desaguaria, cabe suponer. De todas formas, la excavación posterior de algunos solares contiguos ha permitido definir toda una insula, que sospechamos corresponde a una única mansión urbana.

\section{Instalaciones termales de la calle Clérigos (lám. I, 2)}

Corresponden a un solar excavado por mi en 1988 y situado en el extremo oeste de la Plaza Mayor, sin duda el antiguo foro, acera occidental de la calle Obispo Aguirre, al que limita por su lado meridional la calle Clérigos; de ahí su nombre.

Las instalaciones termales de este edificio romano, sólo muy parcialmente excavado, correspondian a cinco o seis estancias de diversa na-

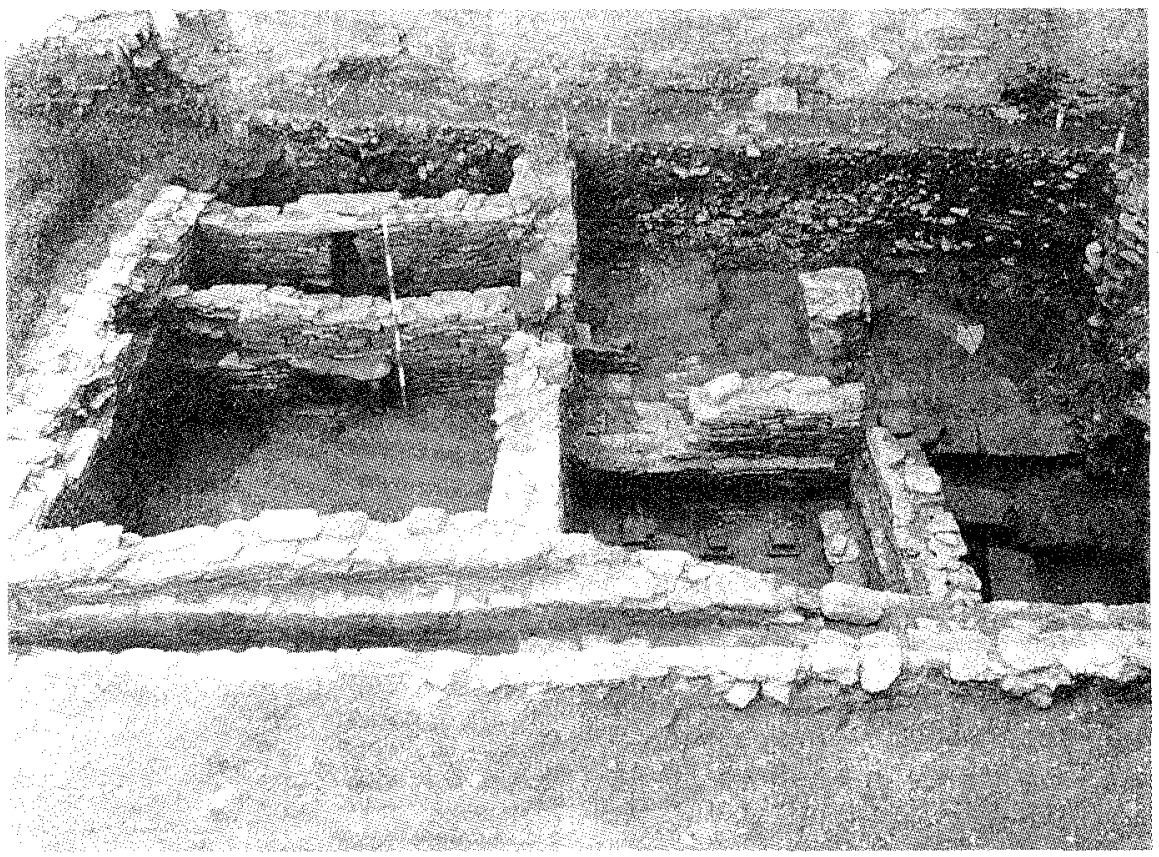

Lám. I, 2. Rua Clérigos. 
turaleza y dimensiones conservadas a notable altura, dado que correspondian a los sectores de sótano que todas ellas habian poseído.

Como en el caso de las de Santo Domingo, la naturaleza termal de estas instalaciones vino rápidamente sugerida por la aparición de un hipocausto en una de las estancias y sendos canales de carga y drenaje a la vera de esa misma y de otras contiguas. Lo fragmentario de las excavaciones no permitió precisar demasiado en lo que al funcionamiento general de la instalación respecta, pero intentaremos aproximarnos a la realidad, tratando de apurar al máximo los datos con que contamos.

En primer lugar, como en el caso de Santo Domingo, existe un canal exterior y contiguo al muro de cierre, que dobla en ángulo recto, como aquél, para abastecimiento de agua limpia. No se ha podido detectar comunicación alguna con las estancias termales, pero ello no constituye obstáculo alguno, dado el grado de arrasamiento y deterioro que se percibe en las estructuras. Por el contrario, existe en nuestro caso otro conducto de drenaje situado a un nivel inferior, que serviría, sin duda alguna, para la evacuación del agua de desecho de las bañeras.

Por otra parte, existe una pequeña estancia de 2 por $2,75 \mathrm{~m}$ con vestigios de suspensurae en su suelo y repisa en sus cuatro lados, como para apoyar el suelo de una piscina, comunicada mediante boquete con otra habitación de mayores dimensiones, 3,50 por $3 \mathrm{~m}$, y contigua a ella por el lado sur. No hemos dudado en identificarla con el caldarium; de lo contrario no tendría demasiado objeto la existencia de suspensurae. Ahora bien, la ausencia de comunicación con otros recintos que no sean la sala contigua aludida y la circunstancia de que esta segunda se encuentre mucho más cerca del praefurnium, y por lo tanto del foco principal de calor, me llevan a pensar que, tal vez, nos las hayamos con un laconicum o sudatorium suficientemente conocido en el mundo romano. En cualquier caso, la ausencia de suspensurae es manifiesta y está pidiendo un piso sustentado mediante vigas, mientras que el perfecto opus signinum de la base y recubrimiento ciel inicio de las paredes dicen mucho en orden a una avara conservación del calor ambiente.

Sigue a la sala anterior un estrecho recinto, 0,75 por $3,50 \mathrm{~m}$, cornunicado con ella mediante boquete de unos $0,60 \mathrm{~m}$ de lado y con la que le sigue, por la parte contraria, a través de otra abertura de similar amplitud, pero de más altura. Pese a no existir evidencias a favor, señales claras de combustión, creemos poder identificar este estrecho recinto con un praefurnium, cuya alimentación se atendería desde la sala contigua occidental, que, por su comunicación indirecta con la fuente principal de calor, sería apta para convertirse, en la planta superior correspondiente, en tepydarium. No dudamos que el frigidarium estaria situado en una po- 
sible estancia contigua si tenemos en cuenta, para ello, el decurso tanto del canal de agua limpia como del de aguas residuales.

De todas maneras, la distribución de funciones propuesta es meramente conjetural, pero no hay esperanza de llegar a más debido a la destrucción anterior de las estructuras que correspondian a otras partes de la construcción.

Aparte de los dos casos expuestos, existen vestigios de otras dos instalaciones privadas, la una en la esquina de la calle Progreso, fachada a la Plaza de Santo Domingo, y la otra en la Rua de Armañá, en un solar recientemente excavado por Paco Herves.

En el primero apareció una pequeña piscina recubierta de opus signinum y sin aparente relación con una gran tubería de plomo que derivaba de su base, pero que correspondia a un nivel anterior, lo que parece indicar una relación ininterrumpida con el agua del lugar en cuestión. No nos atrevemos a aventurar hipótesis comprometidas, a la vista de lo reducido de los vestigios, pero resulta indudable que se trata de una pequeña piscina, sirviese para lo que sirviese.

En el segundo de los casos, la aparición de una exedra y las correspondientes suspensurae nos ha llevado a sospechar de si no se tratará del hipocausto de un caldarium, dado que las prescripciones vitruvianas atribuyen, en general. la forma de exedra a esta parte de las termas. Lo parcial de la excavación, sin embargo, nos hace conducirnos con mucha prudencia, a la vista, sobre todo, de la no aparición, todavía, de los correspondientes canales (lám. II,1).

\section{EL ACUEDUCTO}

La aparición de termas privadas dentro de la ciudad y las correspondientes canalizaciones de agua limpia nos Ilevaron, lógicamente, a suponer la existencia de un acueducto de época romana que pudiese alimentarlas. Sin embargo, la ausencia de vestigios aparentes y hasta de referencias bibliográficas sembraron en nuestro interior la duda de si habría existido o no. A lo más que llegaban los eruditos locales era a afirmar la existencia de una traída de aguas desde el paraje de El Castiñeiro, al noroeste de la ciudad y a menos de un kilómetro, hasta las plazas y edificios de la ciudad en los años centrales del siglo xvIII. Para épocas anteriores, tan sólo en canónigo Pallarés en su Argos Divina, escrita en la segunda mitad del siglo XVII, se atrevió a hablar de un acueducto ro- 


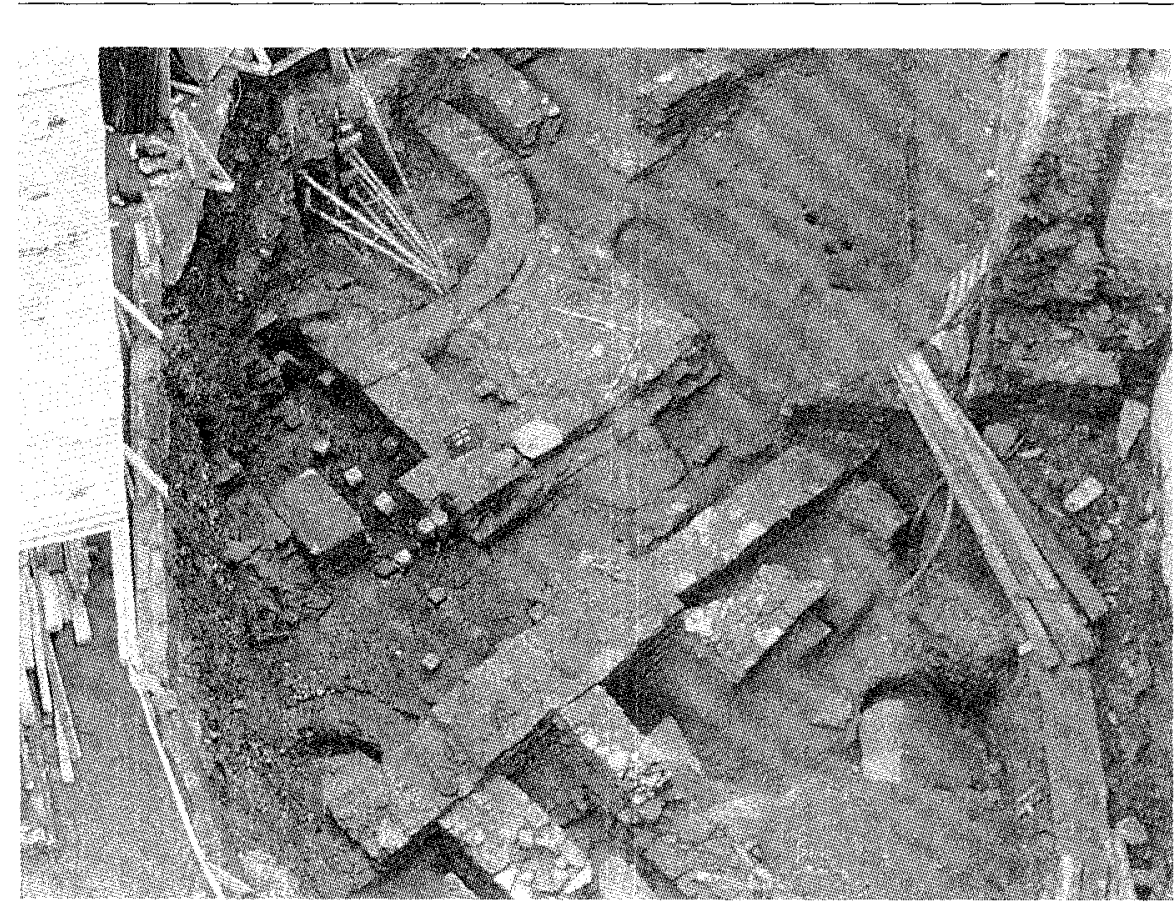

Làm. II, 1.

mairo procedente del paraje de El Castiñeiro en estos términos: «En esta. fuente de sus arrabales, que hoi llaman del Castiñeiro muestra bien ser artificio romano, por lo secretos arcaduces con que entraron el agua a diversas partes de ella, y de su origen se conservaron dos fuentes en los distritos en donde están fundados los dos conventos de Santo Domingo y de San Francisco, de que ai vestigios y memoria en los livros del archivo de la ciudad, y de sus conductos y diligencia para traerla dentro de la ciudad, y información que se ha hecho de cuan necesaria era y sissa que por su Real Cédula permitió su Magestad, para los gastos de traerla: en su nacimiento se manifiesta un conducto de menudos guijarros, y fuerte argamasa, artificio de romanos". Baste con decir que el panorama que describe de las ayudas reales y de las fuentes construidas junto a los dos conventos corresponde a los años centrales del siglo XVI, a juzgar por los testimonios que cita.

Sin embargo, la ausencia de un embalse alimentador del acueducto, tanto derivado del caudal del Miño, imposible si no es a varios kilómetros al norte de la ciudad, como del cauce del Rato, como en el mismo lugar del Castiñeiro nos hicieron dudar en un principio de las aseveraciones de Pallarés. Pero nuestras dudas quedaron disipadas tras un estudio más 
pormenorizado de los vestigios todavía visibles en el Castiñeiro, en donde, junto a las arquetas construidas en el siglo xvIII y todavía en uso a finales de la pasada centuria, hemos decubierto sectores de muro de argamasa romana que hacían de sustentáculo al specus del acueducto romano, uno de cuyos retazos se conservaba intacto todavía bien entrado el siglo xx. Por otra parte, la existencia de canalillos de captación procedentes de diversas partes próximas, que desembocaban en el acueducto e, incluso, de dos áreas diferentes de captación, cuyas canalizaciones confluian, al fin, en una sola nos hicieron comprender que no habia lugar para la existencia de un embalse, ya que se trataba de un acueducto de captación de un rico manantial, de los que la obra vitruviana se hace eco.

De esta manera podíamos explicarnos ya la existencia de retazos de canales de agua limpia en el interior de la ciudad y de sectores del acueducto mismo, así como de sus arquetas de registro, en la plaza de El Ferrol y en la de Santo Domingo. Comprendimos que la traída de agua recorria la línea cimera de las curvas de nivel de la ciudad antigua, entrando por las inmediaciones de la actual puerta de San Fernando y siguiendo por la parte occidental de la Plaza del Ferrol, jardinillos del Palacio de San Marcos y Rua del Progreso. De esta manera, podía repartir su líquido hacia ambas vertientes de la urbe.

\section{TERMAS PÚBLICAS (lám. II,2)}

Que existieron en Lugo no cabe la menor duda, pero a ochocientos metros de distancia de la ciudad y a orillas del Miño.

De su vieja estructura tan sólo se conservan dos salas abovedadas provistas de las hornacinas correpondientes a apoditheria y restos de una tercera que no puede identificarse con seguridad, todo ello englobado bajo la fábrica de un relativamente moderno balneario, en pleno funcionamiento.

Las aguas de este gran naciente son cálidas y sulfurosas, por lo que no fueron precisas instalaciones especiales para la construcción de caldaria, y por otra parte, tanto las aguas del Miño como de las abundantes surgencias acuíferas de las inmediaciones, situadas a más altura que el emplazamiento de las termas, pudieron haber suministrado líquido abundante para el funcionamiento de los frigidaria.

La documentación recopilada al respecto muestra que el establecimiento termal, si bien pasó por etapas de gran abandono, jamás dejó de 


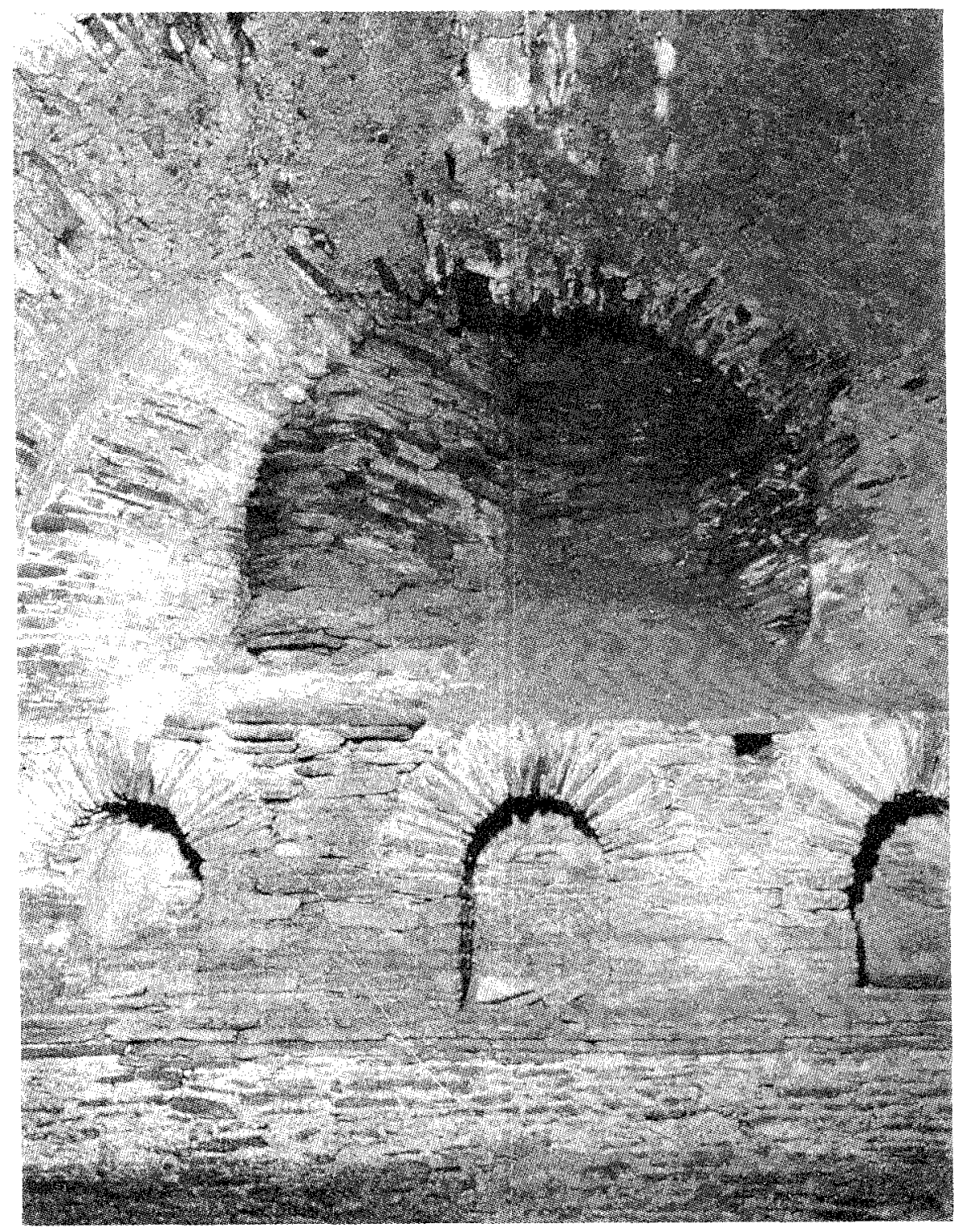

Lám. II, 2. Termas públicas apoditherium. 
funcionar. Todavía en los siglos XVII, XVIII y gran parte del XIX, hasta que se ordenó el levantamiento de las modernas instalaciones, podian contemplarse en el lugar ruinas muchísimo más extensas que las actuales, de naturaleza indudablemente romana. Por ser Molina, Morales y Pallarés los más antiguos testimonios consultados, y porque en sus descripciones se inspiran profundamente los testimonios posteriores, trataremos en las líneas que siguen de transcribir sus observaciones. Afirma Ambrosio de Morales en la descripción de su viaje que "Aquí hay baños con gran edificio de Romanos para ellos, y señaladamente un bravo paredón de argamasa para estorvar que el río Miño, en cuya ribera están, no los cubriese al llegar a ellos...». Molina, unos lustros antes, no es tan explícito en la descripción del edificio, pero habla de una piedra con la data de su fundación, llamándoles los más antiguos de España. Pero en ambos casos se trata de forasteros visitantes. El indígena Pallarés en su ya citada Argos Divina pormenoriza mucho más, como buen conocedor que es de la situación: "No es la menor antigüedad Romana la de los Baños a la orilla del Miño, tienen la virtud de curar qualquiera humor, no siendo galico, dellos trata Gil González, diziendo. Otra maravilla suia es, los baños que tiene saludables, para la vida humana: sus aguas tienen gran fuerça contra enfermedades de frialdades, y vienen a goçar deste beneficio publico enfermos de diferentes provincias; sientese el olor de azufre antes de llegar a ellos.

Tan antiguo es el uso de los baños que tuvieron su principio desde el tiempo de los Romanos, en advertencia de Rodrigo Méndez de Silva, y en la del Corregidor Bovadilla, fue grande el cuidado que tuvieron dellos, haziendo edificios con grande costa, y curiosidad; y aunque el rey don Alonso el 6. Ios prohibió, pareciéndole que aflojaban las fuerzas al os que peleavan, cessó la prohibición con el tiempo o no se executó por tan saludables, los de Lugo publica Molina por los más antiguos de España, con tal artificio resguardados de las avenidas del Miño, que los cercaron los romanos con una cerca de guijarros, y argamasa, y de tal fortaleza, que a pico acerado con dificultad se puede apartar un guijarro de otro; en las ruinas que hoi permanecen, y de una piedra que se reconoció, consta ser grande la antigüedad de su edificio. Dentro del patio de la primera puerta ai algunas bóvedas de ladrillo, y dentro de una dellas un altar para poder decir misa a los enfermos...". El texto no necesita comentarios porque resulta expresivo por sí mismo; si acaso completarlo con el testimonio de Ceán Bermúdez que en el siglo pasado habla de varios restos de arquitectura romana a orillas del Miño y junto a la colina en que se asienta la ciudad, como son unos grandes paredones de argamasa, unos inhiestos y otros caidos y cubiertos en el invierto con las aguas del río. Que fueron baños romanos lo demostrarían ciertos trozos de bóvedas con arcos re- 
bajados, que pudieron haber sido sudaderos de las mismas termas. $Y$ al respecto, aduce los versos de Molina, que los habia contemplado en el siglo XVI:

Tambien hallareis en aquella ciudad los baños antiguos, de quien hay memoria que Plinio los pone tambien en su historia, por eso los pongo por su antigüedad: y su letrero dirá la verdad, demás de mostrallo su viejo edificio ser estas aguas y aqueste artificio obrado en el tiempo de gentilidad

Existe desde hace algún tiempo un plan especial para recuperar las termas y se está ya elaborando otro que lo sustituirá; pero el nivel freático ha impedido hasta la fecha cualquier intervención arqueológica seria, que, no obstante, y en un plazo breve, se pretende acometer.

Las detecciones efectuadas con georradar y otros métodos en el entorno de las termas por especialistas de la universidad de Barcelona, dirigidos por el profesor Alberto Casas, han puesto de manifiesto la existencia de una extensa maraña de estructuras, que demostrarían que el complejo termal, sin ser de los de mayores dimensiones, ocupaba un área relativamente extensa con sus complejas instalaciones. Mientras la arqueología no descubre las características totales del establecimiento tenemos que conformarnos con simples conjeturas, en la certeza de que Lucus, como cualquier ciudad romana de cierta importancia, contó con vestigios urbanísticos relevantes concretados en sus termas públicas y privadas, en su acueducto, en su red de cloacas y la magnificencia y ornato de algunas de las construcciones hasta el presente exhumadas.

De todo ello se irá dando cumplida cuenta en breve, en varios extensos volúmenes que están ya siendo elaborados y que versan esencialmente sobre los descubrimietos arqueológicos operados en la ciudad desde el año 1986.

\section{RESUMEN}

Durante los cinco últimos años de excavaciones arqueológicas en la ciudad de Lugo, han aparecido varios establecimientos termales de uso privado, que vienen a sumarse a las ya archiconocidas termas públicas 
romanas de la ciudad. En el presente artículo se da cuenta somera de todos estos hallazgos.

\section{ABSTRACT}

During the last five years of archaeological diggings in the city of Lugo, some thermal sites of private use have been discovered, in addition to the very well known Roman ones of public use in the city. The article herebolow deals, in a general way, with all these discoveries.

\section{BIBLIOGRAFIA}

Han resultado guía valiosa para nuestra disertación los estudios de carácter general que vamos a enumerar brevemente.

Benolt, F., «Thermae», en Ch. Daremberg-Ed. Saglio, Dictionnaire des Antiquités Grecques et Romaines, V, $214 \mathrm{ss.} \mathrm{Graz} 1969$.

SAGLIO, E., «Balneum, Balneae», idem, I, 648 ss.

Mc Donald, W. L., The Architecture of the Roman Empire. London 1965.

WACHER, J., The Towns of Roman Britain. London 1974.

WHITE, D., Greek and Roman Technology. London 1984.

Cagiano de Azevedo, M., Casa, Cittá e Campagna nel Tardo Antico e nell'Alto Medievo. Galatina 1986

VV. AA., L'Urbs, Espace urbain et histoire (ler siècle av. J. C. - Ille siècle ap. J. C.). Roma 1987.

Gros, P.-Torellı, M., Storia dell'urbanistica. /l Mondo Romano. Roma 1988. Especialmente valioso.

Ramallo Asensio, S., La Ciudad Romana de Carthago Nova: La documentación arqueológica. Murcia 1989.

Para la obra vitruviana

Morolli, G., L'Architectura di Vitruvio. Firenze, 1988.

Gros, P., "Structures et limites du compilatum vitruvien», Latomus, XXXIII, 1974.

Sobre investigación arqueológica en las ciudades vecinas,

I.P.P.C, «As termas de Bracara Augusta», Arqueología, 18, 1988.

LUengo Martinez, J. M., "Astorga Romana. Excavaciones del Plan Nacional 1954-61", NAH, V, 1956-61.

Mañanes, T., Astorga Romana y su entorno. Estudio Arqueológico. Valladolid 1983. 
Ya concretamente, sobre la ciudad de Lugo y sus termas en el transcurso de la Edad Moderna,

Sagrario Molina, B., Descripción del Reyno de Galizia. Mondoñedo 1550 (reed. 1949 e introd. de Filgueira Valverde).

de Morales, A., Viage de Ambrosio de Morales por orden del rey D. Phelipe II. A los reynos de León, y Galicia, y Principado de Asturias. Año de M. D. LXXII (publicado por le P. Enrique Flórez en Madrid 1965, pág. 115 ss. ).

Pallares, J., y Galoso, Argos Divina. Santiago 1700, reedición en Lugo 1903 por la «Imprenta del Norte de Galicia”.

Alusiones en Ceán Bermúdez, Madoz y diversos eruditos locales que repiten, de alguna manera, las noticias suministradas por aquellos autores antiguos. 